\title{
Metal Additive Manufacturing: A Review
}

\author{
William E. Frazier
}

\author{
(Submitted February 24, 2014; published online April 8, 2014)
}

\begin{abstract}
This paper reviews the state-of-the-art of an important, rapidly emerging, manufacturing technology that is alternatively called additive manufacturing (AM), direct digital manufacturing, free form fabrication, or 3D printing, etc. A broad contextual overview of metallic AM is provided. AM has the potential to revolutionize the global parts manufacturing and logistics landscape. It enables distributed manufacturing and the productions of parts-on-demand while offering the potential to reduce cost, energy consumption, and carbon footprint. This paper explores the material science, processes, and business consideration associated with achieving these performance gains. It is concluded that a paradigm shift is required in order to fully exploit AM potential.
\end{abstract}

Keywords fabricated metal, modeling processes, powder metallurgy

\section{Introduction}

ASTM has defined additive manufacturing (AM) as "a process of joining materials to make objects from 3D model data, usually layer upon layer, as opposed to subtractive manufacturing methodologies. Synonyms: additive fabrication, additive processes, additive techniques, additive layer manufacturing, layer manufacturing, and freeform fabrication" (Ref 1). This definition is broadly applicable to all classes of materials including metals, ceramics, polymers, composites, and biological systems. While AM has been around as a means of processing materials for, arguably, over two decades, it has only recently begun to emerge as an important commercial manufacturing technology.

In 2009, Bourell et al. (Ref 2) published a roadmap for AM based on a workshop of 65 key people in AM. Their report explored important facets of the AM including:

- Design

- Process modeling and control

- Materials, processes, and machines

- Biomedical applications

- Energy and sustainability applications

In 2010, Frazier (Ref 3) published the results of a Navy workshop entitled "direct digital manufacturing (DDM) of metallic components: affordable, durable, and structurally efficient aircraft." A vision of parts on demand when and where they are needed was articulated. Achieving the vision state would enhance operational readiness, reduce energy consumption, and reduce the total ownership cost of naval aircraft through the use of AM. Specific technical challenges

William E. Frazier, Naval Air Systems Command, Patuxent River, MD. Contact e-mail: frazierwe@gmail.com. were identified to address the quantitative objectives in the areas of (i) innovative structural design, (ii) qualification and certification, (iii) maintenance and repair, and (iv) DDM science and technology. Top level findings include

- High priority should be given to developing integrated in-process, sensing, monitoring, and controls. Machineto-machine variability must be understood and controlled.

\begin{tabular}{|ll|}
\hline & \multicolumn{1}{c|}{ Nomenclature } \\
\hline 3D & Three dimensional \\
AM & Additive manufacturing \\
BCA & Business case analysis \\
BREW & Business resource efficiency and waste \\
CO2PE! & Cooperative effort on process emissions in \\
& manufacturing \\
DDM & Direct digital manufacturing \\
DFE & Design for environment \\
DMLS & Direct metal laser sintering \\
DoD & Department of defense \\
EBPB & Electron beam powder bed \\
EBFFF & Electron beam free form fabrication \\
EIA & Environmental impact assessment \\
EISS & Environmental impact scoring systems \\
FFF & Free form fabrication \\
HIP & Hot isotactic pressing \\
IDA & Institute for defense analysis \\
LAM & Laser additive manufacturing \\
LBPB & Laser beam powder bed \\
LCA & Life-cycle analysis \\
LENS & Laser engineered net shaping \\
NIST & National institute for standards and technology \\
PTAS FFF & Plasma transferred arc selected free form fabrication \\
SBIR & Small business innovative research \\
SLM & Selective laser melting \\
SLS & Selective laser sintering \\
SMD & Shaped metal deposition \\
WAAM & Wire and arc additive manufacturing \\
WFLB & Wire fed laser beam \\
&
\end{tabular}


- Alternatives to conventional qualification methods must be found; these are likely based upon validated models, probabilistic methods, and part similarities. Part-by-part certification is costly, time consuming, and antithetical to achieving the Navy's vision of producing and using AM parts on demand.

- Priority should be given to the development of integrated structural and materials design tools. This is needed to accelerate the adoption of AM by the aircraft design community and to promote new innovative structural designs needed to save energy and weight.

- Underline science of DDM needs to be developed. Physics-based models are needed relating microstructure, properties, and performance. New alloys must be developed to optimize properties. An understanding of how to control fatigue properties and reduce surface roughness, must be developed.

Hederick (Ref 4) published a review of AM of metals in 2011. Presented is a nice summary of the various AM technologies and the dominate AM equipment manufacturers. AM equipment was broadly divided into powder bed systems, laser powder injection systems, and free form fabrication (FFF) systems. Some of the major findings of the report include:

- Materials processed using AM experience complex thermal processing cycles. There is a need to better understand the link between microstructure, processing, and properties for AM fabricated parts, as well as developing an AM materials database. He reports that there has been a lot of work on Ti-6Al-4V, but not so much on other alloys.

- There is a need reduce the variance in properties and quality from machine-to-machine across materials and machine types. Therefore, closed-loop feedback control and sensing systems with intelligent feed forward capability needs to be developed. Further, the ruggedization of AM equipment is needed.

- AM can be applied to the manufacturing of parts that cannot be made with standard machining practices. This possibility enables novel design methodologies.

NIST held a workshop in December of 2012 and recently published the results "Measurement Science Roadmap for Metal-Based Additive Manufacturing" (Ref 5). Important technology challenges were identified in the areas (i) AM materials, (ii) AM process and equipment, (iii) AM qualification and certification, and (iv) AM modeling and simulation. The technology development opportunities identified include:

- Robust in situ process monitoring techniques including sensors for measuring and monitoring AM processes and products.

- A metals design allowable and performance capability database

- A shared 3rd party database

- An expert system for AM design

- Validated physics and properties-based models.

Common to the aforementioned work is the recognition that $\mathrm{AM}$ is a transformative technology. AM will impact component design, cost, and product delivery; it will affect global business models and logistics; it should enable increased energy efficiency and lower environmental impact.

Standardization of AM processes is an important step in the advancement of metals AM and is currently on-going. In 2009, the American Society for Testing and Materials (ASTM) F42 Committee on AM Technologies was created to guide the development of international standards in AM. ASTM F2924 Specification for AM Titanium-6 Aluminum-4 Vanadium with Powder Bed Fusion was approved in 2012. Other important standardizations were created that ultimately assist the advancement of AM including, ASTM F2792 standardized AM terminology (2009) and ASTM F2915 Specification for AM File Format (2011). Standardization of the file formats to additive manufacturing file (AMF) format allows designs to be transferred between different hardware and software systems and was developed to support full-color multi-material geometries with microstructure and material gradients.

The 2009 RapidTech paper by Bourell et al. (Ref 2) identified the need for a National test bed Center with experts that would facilitate the leveraging of equipment and human resources. In August 2012, the National Additive Manufacturing Innovation Institute, now called America Makes, was formed by President Obama as part of the National Network for Manufacturing Innovation. Based in Youngstown, Ohio, NAMII serves as a national resource in expertise for AM. NAMII's mission is to "accelerate AM technologies to the U.S. manufacturing sector and increase domestic manufacturing competitiveness by fostering a highly collaborative infrastructure for the open exchange of AM information and research; facilitating the development, evaluation, and deployment of efficient and flexible AM technologies; and educating students and training workers in AM technologies to create an adaptive, leading workforce.'[NAMII website] NAMII has recently funded six AM projects, three on metals, and three on polymers.

\section{Metallic Additive Manufacturing Systems}

AM system may be classified/categorized in terms of the material feed stock, energy source, build volume, etc. Table 1 is a selected list of equipment manufactures and their equipment. In this table, manufacturing systems are divided into three broad categories (although there are many more): (i) powder bed systems, (ii) powder feed systems, and (iii) wire feed systems. The energy source (electron beam, laser, arc, etc.) for these systems is also provided.

\subsection{Powder Bed Systems}

All the powder bed systems are manufactured by companies located outside the United States. In general, the build volumes of these units are less than $0.03 \mathrm{~m}^{3}$. ARCAM, a Swedish company, manufactures the only powder bed electron beam system, the ARCAM A2.

Figure 1 is a schematic of a generic powder bed system. A powder bed is created by raking powder across the work area. The energy source (electron beam or laser beam) is programmed to deliver energy to the surface of the bed melting or sintering the powder into the desired shape. Additional powder is raked across the work area, and the process is repeated to create a solid three dimensional component. The advantages of 
Table 1 Representative AM equipment sources and specifications

\begin{tabular}{|c|c|c|c|}
\hline System & Process & Build volume (mm) & Energy source \\
\hline \multicolumn{4}{|l|}{ Powder bed } \\
\hline ARCAM (A2)(a) & EBM & $200 \times 200 \times 350$ & $7 \mathrm{~kW}$ electron beam \\
\hline EOS (M280)(b) & DMLS & $250 \times 250 \times 325$ & 200-400 W Yb-fiber laser \\
\hline Concept laser cusing (M3)(b) & SLM & $300 \times 350 \times 300$ & $200 \mathrm{~W}$ fiber laser \\
\hline MTT (SLM 250)(b) & SLM & $250 \times 250 \times 300$ & 100-400 W Yb-fiber laser \\
\hline Phenix system group (PXL)(c) & SLM & $250 \times 250 \times 300$ & $500 \mathrm{~W}$ fiber laser \\
\hline Renishaw (AM 250)(d) & SLM & $245 \times 245 \times 360$ & 200 or $400 \mathrm{~W}$ laser \\
\hline Realizer (SLM 250)(b) & SLM & $250 \times 250 \times 220$ & 100,200 , or $400 \mathrm{~W}$ laser \\
\hline Matsuura (Lumex Advanced 25)(e) & SLM & $250 \times 250$ diameter & $\begin{array}{l}400 \mathrm{~W} \text { Yb fiber laser; hybrid } \\
\text { additive/subtractive system }\end{array}$ \\
\hline \multicolumn{4}{|l|}{ Powder feed } \\
\hline Optomec (LENS 850-R)(f) & LENS & $900 \times 1500 \times 900$ & 1 or $2 \mathrm{~kW}$ IPG fiber laser \\
\hline POM DMD (66R)(f) & DMD & $3,200^{\circ} \times 3^{\circ}, 670^{\circ} \times 360^{\circ}$ & 1-5 $\mathrm{kW}$ fiber diode or disk laser \\
\hline Accufusion laser consolidation(g) & $\mathrm{LC}$ & $1,000 \times 1,000 \times 1,000$ & Nd:YAG laser \\
\hline Irepa laser $($ LF 6000)(c) & LD & & Laser cladding \\
\hline Trumpf(b) & $\mathrm{LD}$ & $600 \times 1,000$ long & \\
\hline Huffman (HC-205)(f) & LD & & $\mathrm{CO}_{2}$ laser clading \\
\hline \multicolumn{4}{|l|}{ Wire feed } \\
\hline Sciaky (NG1) EBFFF(f) & EBDM & $762 \times 483 \times 508$ & >40kW@60kVwelder \\
\hline MER plasma transferred arc selected $\operatorname{FFF}(\mathrm{f})$ & PTAS FFF & $610 \times 610 \times 5,182$ & $\begin{array}{l}\text { Plasma transferred arc using two } \\
\text { 350A DC power supplies }\end{array}$ \\
\hline Honeywell ion fusion formation(f) & IFF & & Plasma arc-based welding \\
\hline
\end{tabular}

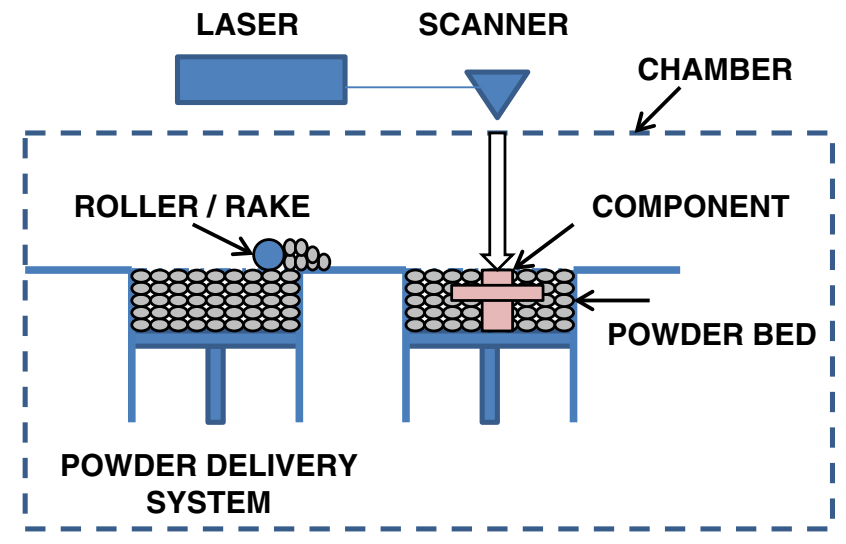

Fig. 1 Generic illustration of an AM powder bed system

this system include its ability to produce high resolution features, internal passages, and maintain dimensional control.

\subsection{Powder Feed Systems}

A generic illustration of AM powder feed systems is shown in Fig. 2. The build volumes of these systems are generally larger (e.g., $>1.2 \mathrm{~m}^{3}$ for the Optomec LENS 850-R unit). Further, the powder feed systems lend themselves more readily to build volume scale up than do the powder bed units. In these systems, powders are conveyed through a nozzle onto the build surface. A laser is used to melt a monolayer or more of the powder into the shape desired. This process is repeated to create a solid three dimensional component. There are two dominate types of systems in the market. 1. The work piece remains stationary, and deposition head moves. 2. The deposition head remains stationary, and the work piece is moved. The advantages of this type of system include its larger build

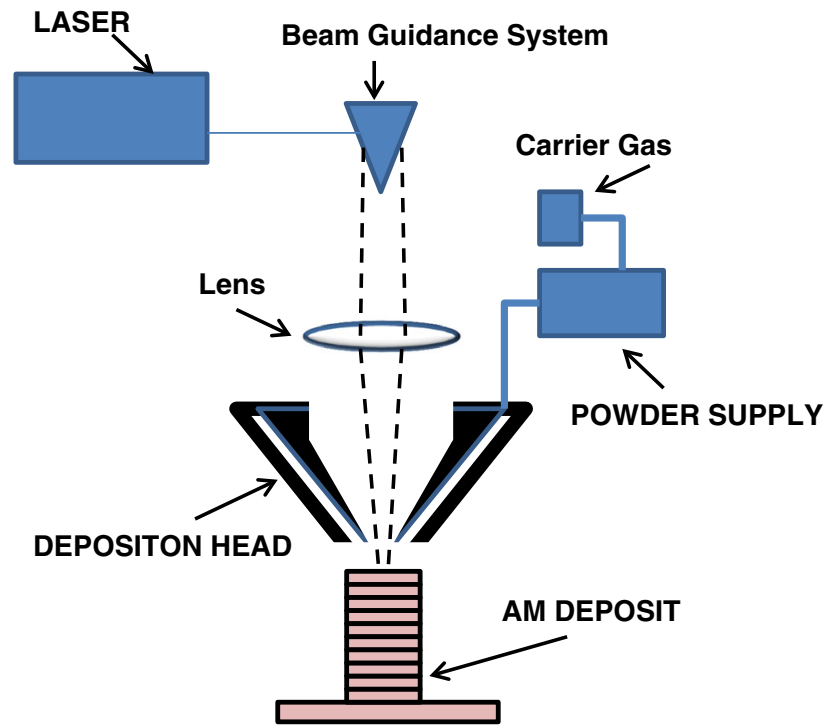

Fig. 2 Generic illustration of an AM powder feed system

volume and its ability to be used to refurbish worn or damaged components.

\subsection{Wire Feed Systems}

A schematic of a wire feed unit is shown in Fig. 3. The feed stock is wire, and the energy source for these units can include electron beam, laser beam, and plasma arc. Initially, a single bead of material is deposited and upon subsequent passes is built upon to develop a three dimensional structure. In general, wire feed systems are well suited for high deposition rate processing and have large build volumes; however, the 
fabricated product usually requires more extensive machining than the powder bed or powder fed systems do.

In summary, there are a large number of diverse AM pieces of equipment commercially available. These may be broadly characterized as powder bed, powder fed, and wire fed systems. There are distinct advantages to each type of system dependent upon the intended applications, e.g., repair and refurbishment, small part fabrication, large part fabrication.

\section{Technology Challenges}

\subsection{Process Controls, Sensors and Models}

In 2012, the Institute for Defense Analysis (Science and Technology Policy Institute) reported on status and opportunities of AM (Ref 6). A key finding was that additional R\&D resources need to be applied to technical challenges such as process control and modeling. There is a need for real-time, closed-loop process controls and sensor in order to ensure quality, consistency, and reproducibility across AM machines (Ref 3,6$)$. Since the properties of AM materials are tied to the immediate past processing history (e.g., build temperature, part geometry), sensors are being developed to measure melt pool size and shape as well as melt pool and build temperatures. These concepts are being explored under Navy SBIR projects (Ref 7). These data in combination with predictive algorithms are needed in order to adjust and control process parameters in real time to ensure quality, consistency, and reliability.

\subsection{Metallurgy}

To date, there have been only a limited number of commercial alloys used in AM. Some of these are presented in Table 2. As the AM field matures, it is clear to this author that new alloys will need to be developed in order to exploit the advantages of AM. Ti-6Al$4 \mathrm{~V}$ has been by far the most extensively investigated. This can be attributed to the strong business case that can be developed for complex, low production volume titanium parts.

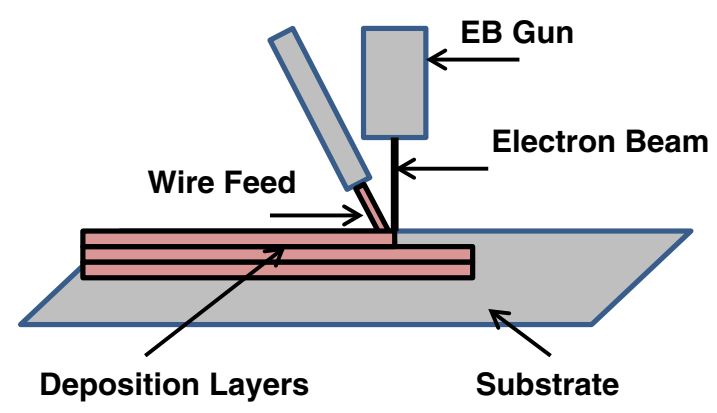

Fig. 3 Generic illustration of an AM wire feed system

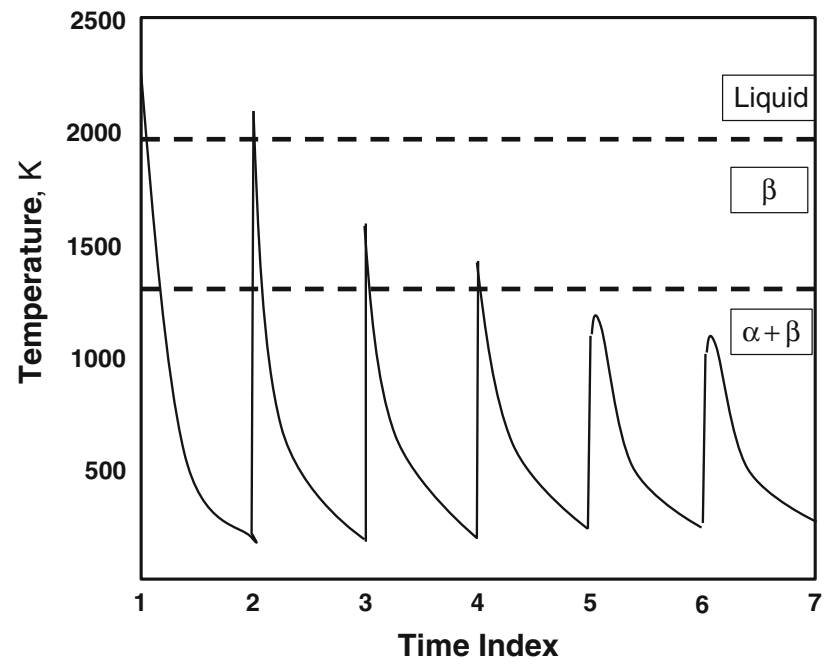

Fig. 4 Notional thermal profile of a single layer of Ti-6Al-4V during AM
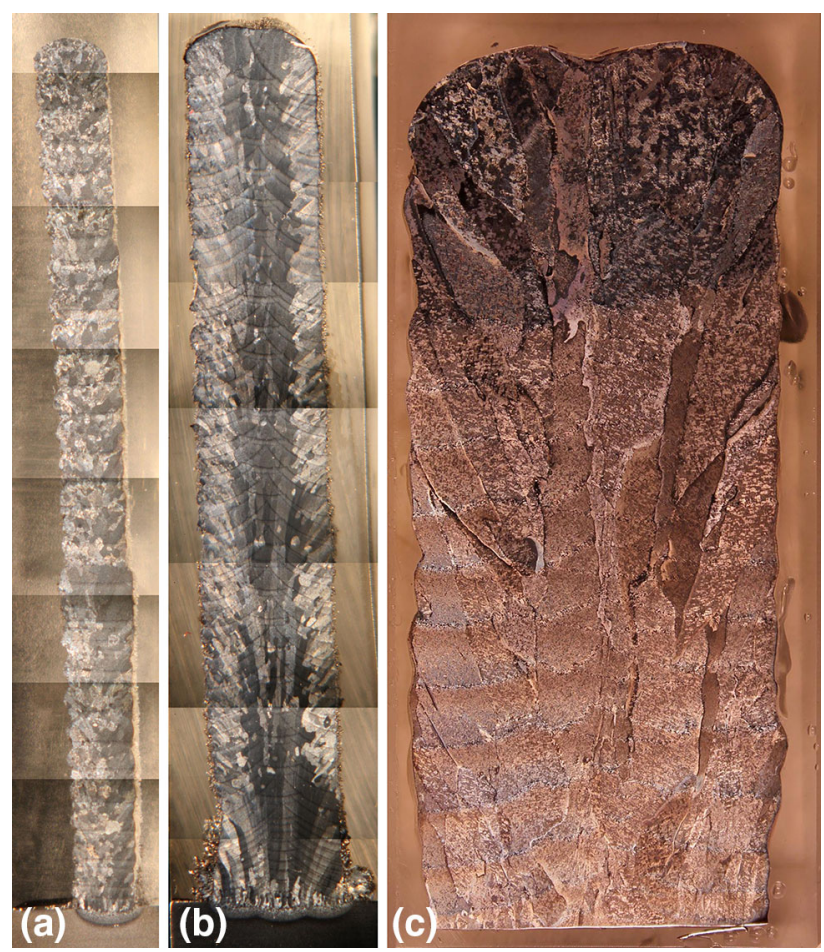

Fig. 5 Macro-graphic images of additive manufacture Ti-6Al-4V: (a) laser powder blown single bead wide, (b) laser powder blown three bead wide, and (c) electron beam wire three bead wide

Table 2 Selected alloys commercially used in AM processing

\begin{tabular}{llllll}
\hline Titanium & Aluminum & Tool steels & Super alloys & Stainless steel & Refractory \\
\hline Ti-6Al-4V & Al-Si-Mg & H13 & IN625 & $316 \& 316 \mathrm{~L}$ & MoRe \\
ELI Ti & 6061 & Cermets & IN718 & 420 & Ta-W \\
CP Ti & & Stellite & 347 & CoCr \\
$\gamma$-TiAl & & & PH 17-4 & Alumina \\
\hline
\end{tabular}



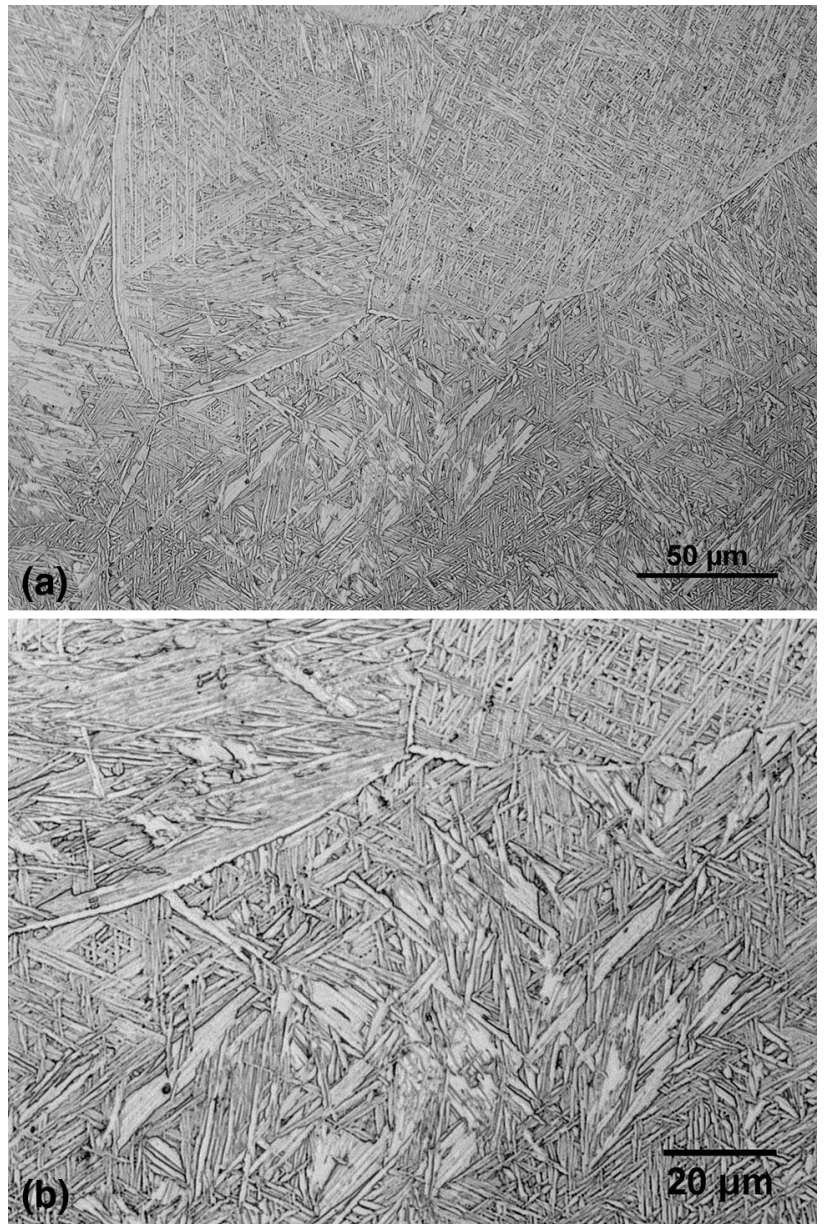

Fig. 6 Optical micrographs of laser powder blown produced $\mathrm{Ti}-6 \mathrm{Al}-4 \mathrm{~V}$ in the as-fabricated condition

$\mathrm{AM}$ is a layer by layer manufacturing process. A single layer of metal is "cast" upon a previous layer resulting in a complex, time dependent temperature profiles within the part being fabricated. The result is that the alloy may experience repeated solid state and liquid-solid phase transformations. Figure 4 is a notional thermal profile for a single layer AM processed Ti-6Al-4V (Ref 8, 9). In this graph, the temperature of a single layer is mapped showing that this layer experienced two liquidsolid transformation and two alpha-beta transformations. These profiles are dependent upon a number of variables including the $\mathrm{AM}$ equipment, the time between passes, and the size of the part being fabricated.

In general, AM is a relatively rapid solidification process. Zheng et al. (Ref 10-12) report cooling rates for the LENS process to be between $10^{3}$ and $10^{4} \mathrm{~K} / \mathrm{s}$. Vilaro et al. (Ref 10) reported cooling rates of $10^{4} \mathrm{~K} / \mathrm{s}$ for SLM. Zheng et al. (Ref 12) used dendrite arm spacing to establish the cooling rate of LENS processed 316L. Further, the heat flow in AM processes is directional frequently resulting in columnar microstructures. Kobryn and Semiatin developed a solidification map for Ti-6Al-4V using Nd:YAG laser and a $\mathrm{CO}_{2}$ Laser. Using this method, the maps of columnar, mixed, and equiaxed structures were developed as a function of cooling rate, $G(K / s)$, versus solidification rate, $\mathrm{R}(\mathrm{cm} / \mathrm{s})$ (Ref 13$)$.

The combined effect of rapid solidification, directional cooling, and phase transformations induced by repeated thermal
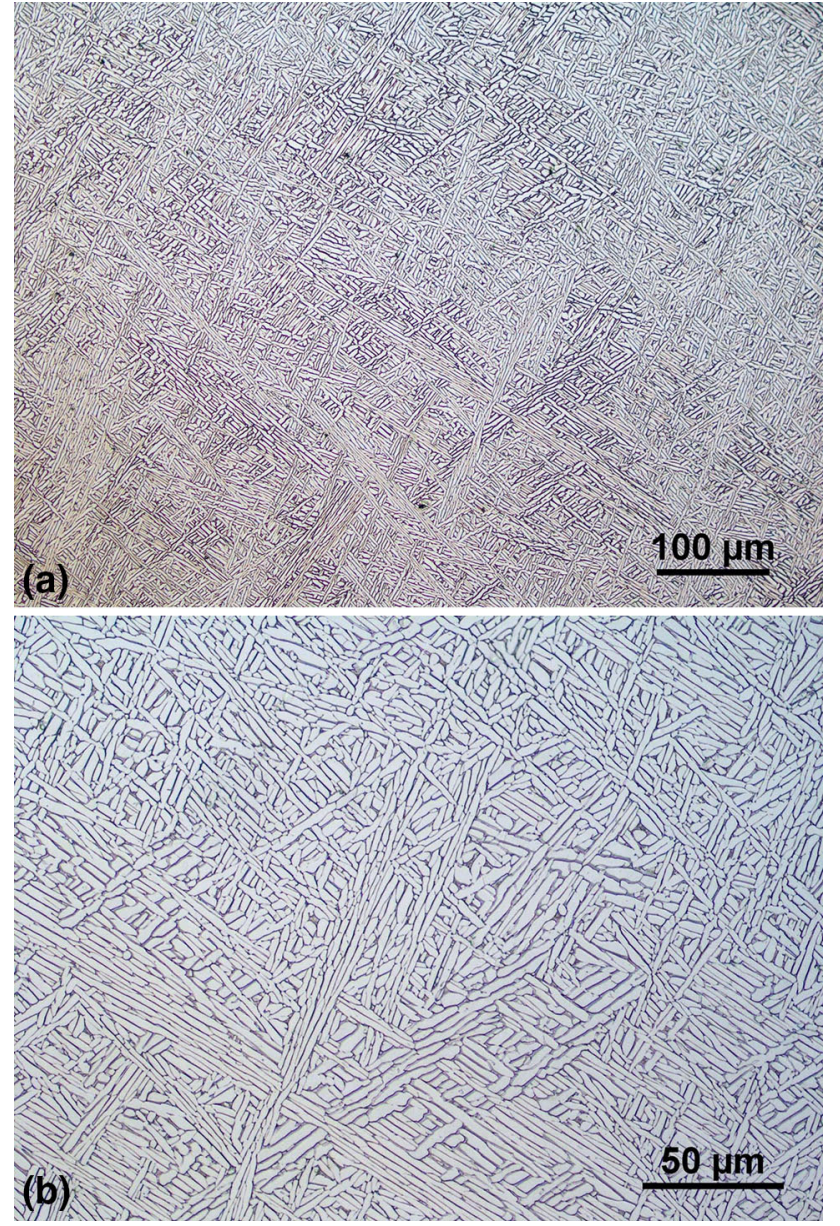

Fig. 7 Optical micrographs of electron beam wire produced Ti-6Al$4 \mathrm{~V}$ in the as-fabricated condition

cycles has a profound influence on the microstructures of the materials deposited. Rapid solidification reduces elemental partitioning and extends solid solubility and can result in metastable phase formation. Directional heat extraction may result in preferred directionality in grain growth. Repeated thermal cycles have a possible complex set of effects, including microstructural banding, i.e., microstructural differences between depositions layers (Ref 1, 14-16). For Ti-6Al-4V, Vilaro et al. reported large columnar grains $150-\mu \mathrm{m}$ wide; re-melting resulted in a strong texture as a result of epitaxial growth nucleating on columnar grain sites. A strong anisotropy in fracture behavior was also noted and attributed to manufacturing defects. Some of the typical defects observed in the SLM process were micro-porosity and lack of fusion. The microporosity $(10-50 \mu \mathrm{m}$ at less than 1 vol.\%) was reported and attributed to gas entrapment (Ref 11$)$ as was the alpha prime phase due to rapid cooling.

Macro-graphic images of additive manufacture Ti-6Al-4V are presented in Fig. 5. Figure 5(a) and (b) is materials produced by ARL Penn States laser beam, powder blown system. Figure 5(c) is produced by NASA's electron beam, wire fed system. The typically observed columnar grains are seen growing in the z-direction (i.e., perpendicular to the build plane) and in the direction of heat extraction. Although columnar grain growth is observed in materials produced by both systems, it is less prominent in the single pass laser 
system. Optical micrographs of these same materials are presented in Fig. 6 and 7. In general, the microstructure of the laser powder blown materials appears finer in structure than those produced by the wire fed system. This is attributed to the larger melt pool (as likely slower cooling rates) associated with the wire fed system.

Wang et al. reported that fatigue cracks initiating at pores close to the surface for WAAM processed Ti-6Al-4V. Porosity is attributed to the absorption of $\mathrm{N}, \mathrm{O}$, and $\mathrm{H}$ in the molten weld pool; this then nucleates at the solid-liquid interface during solidification. The fatigue life of most of the specimens exceeded the baseline; however, a small number failed at a very early stage of testing (Ref 17).

In summary, AM alloys have a complex thermal history involving directional heat extraction, and repeated melting and rapid solidification. Typically, AM fabricated alloys also experience repeated solid state phase transformations. These factors introduce complexities not typically found in conventional processes.

\subsection{Mechanical Properties}

The focus of this section is on the mechanical properties of AM processed Ti-6Al-4V and IN 625 and IN 718.

\subsection{Ti-6Al-4V}

The AMS 4999 specification lists the minimum mechanical properties for laser AM produced Annealed Ti-6Al-4V in Table 3 (Ref 18). Where $X$ is in the direction of deposition; $Y$ is transverse to the $X$ direction and in the plane of deposition; $Z$ is the direct normal to the plane of deposition. The specification calls for post AM thermal processing, viz., HIP or thermal anneal treatment. The HIP cycle is nominally $100 \mathrm{MPa}$ and $926{ }^{\circ} \mathrm{C}$ for $2-4 \mathrm{~h}$ and furnace cooled below $427{ }^{\circ} \mathrm{C}$. The thermal anneal is nominally $913{ }^{\circ} \mathrm{C}$ for $2-4 \mathrm{~h}$ and furnace cooled below $427{ }^{\circ} \mathrm{C}$. It is worth noting that both the HIP temperature and the thermal anneal temperatures are within the $\alpha-\beta$ phase field close to the $\beta$-transus temperature of $1000{ }^{\circ} \mathrm{C}$.

The static properties of AM processed Ti-6Al-4V reported are comparable to wrought product form (Ref 19-21). Some values reported for M280 and ARCAM processed materials are presented in Table 4 (Ref 19).

It is observed that the yield and ultimate tensile strengths of the AM process alloys exceed the typical value of wrought Ti-6Al-4V. However, it may also be noted that the ductility is slightly lower than that of the wrought alloy, and there is anisotropy associated with the build direction. Further, there is a slight anisotropy in yield strength and ultimate tensile strength associated with the build directions.

For wire and arc additive manufacturing (WAAM) fabricated Ti-6Al-4V, a larger anisotropy was observed in Table 5 (Ref 9). Tensile properties in the build direction are observed to be lower than in the $X-Y$ plane of build. Wang et al. observed that the mean fatigue life was slightly greater than that of forged Ti-6Al-4V.

\subsection{Nickel Superalloys}

Microstructure and mechanical properties of ARCAM (EBM) produced IN 625 are reported in Table 6 (Ref 14). Samples were HIPed at $1393 \mathrm{~K}, 100 \mathrm{MPa}$ for $4 \mathrm{~h}$. In the as-fabricated condition, the microstructure was found to be columnar with grains up to $20 \mu \mathrm{m}$ in width. Following HIP, the columnar grains recrystallized, and the metastable $\gamma^{\prime \prime}\left(\mathrm{Ni}_{3} \mathrm{Nb}\right)$ dissolved. They reported that their work demonstrated unusual microstructures and microstructural (columnar precipitate) architectures which opened the door to microstructural design.

The static mechanical properties of EBM IN 625 are reported in Table 6 . In the as-fabricated condition, the ductility is equivalent to that of the wrought and annealed IN 625, while the yield strength is $9 \%$ lower. Upon HIPing, yield strength decreases $26 \%$, while the ductility increases by $57 \%$.

Baufeld investigated the deposition of IN718 via shaped metal deposition (SMD). The properties of this weld-based tungsten inert gas welding AM process were compared to those of laser and electron beam processes, Table 7 (Ref 22). The microstructure of the SMD IN718 was described as columnar with a fine distribution of dendrites. The mechanical properties of the SMD alloy may be considered superior to those of the as-cast IN718, but inferior to those for other AM processes. It is noteworthy that the tensile strength and elongation for all the AM processed materials exceeded that of the as-cast.

\subsection{Fatigue, Porosity, and Surface Roughness}

Table 8 presents the fracture toughness and fatigue strength (a) $10^{7}$ cycles and $R=0.1$ for ARCAM produced Ti-6Al-4V

Table 4 Static properties of M280 and ARCAM processed Ti-6Al-4V

\begin{tabular}{lccccc}
\hline & $\begin{array}{c}\text { M280, } \\
\text { Typical } \\
\text { wrought }\end{array}$ & $\begin{array}{c}\text { HIP + solution } \\
\text { heat treat }\end{array}$ & ARCAM, HIP \\
\hline Orientation & $\mathrm{n} / \mathrm{a}$ & $X-Y$ & $Z$ & $X-Y$ & $Z$ \\
YS, MPa & 828 & 887 & 946 & 848 & 841 \\
UTS, MPa & 897 & 997 & 1010 & 946 & 946 \\
Elongation & $15 \%$ & 11.4 & 13.9 & 13.2 & 13.9 \\
\hline
\end{tabular}

Table 5 Static mechanical properties of WAAM fabricated Ti-6Al-4V

\begin{tabular}{lrc}
\hline Property & $\boldsymbol{X}-\boldsymbol{Y}$ & $\boldsymbol{Z}$ \\
\hline YS, MPa & 950 & 803 \\
UTS, MPa & 1033 & 918 \\
\hline
\end{tabular}

Table 3 AMS 4999 Ti-6Al-4V minimum tensile properties (Ref 18)

\begin{tabular}{lccc}
\hline UTS, MPa & UTS, MPa & YS, MPa & YS, MPa \\
$X$-direction & $Y$ - \& $Z$-direction & $X$-direction & Y- \& Z-direction \\
\hline 896 & 841 & 800 & 745 \\
\hline
\end{tabular}


Table 6 Static mechanical properties of AM fabricated IN625 (Ref 14)

\begin{tabular}{lccc}
\hline Process & Yield strength, MPa & Tensile strength, MPa & \% Elongation \\
\hline Wrought (annealed) & 450 & 890 & 44 \\
As-fabricated EBM & 410 & 750 & 44 \\
EBM + HIP & 330 & 770 & 69 \\
Wrought (cold worked) & 1,100 & $\cdots$ & 18 \\
\hline
\end{tabular}

Table 7 Mechanical properties of AM fabricated IN718 (Ref 22)

\begin{tabular}{llll}
\hline AM Process & UTS, MPa & YS, MPa & \% Elongation \\
\hline SMD & $828 \pm 8$ & $473 \pm 6$ & $28 \pm 2$ \\
As-cast & 786 & 488 & 11 \\
Laser & 904 & 552 & 16 \\
EB & 910 & 580 & 22 \\
\hline
\end{tabular}

Table 8 Fatigue and fracture toughness properties of ARCAM produced Ti-6Al-4V (Ref 20)

\begin{tabular}{lccccc}
\hline Process & Orientation & Porosity, \% & $\boldsymbol{K}_{\mathbf{I C}}, \mathbf{M P a} \sqrt{\mathbf{m}}$ & $\mathbf{S T D}, \mathbf{M P a} \sqrt{\mathbf{m}}$ & Fatigue strength at 10 $^{\mathbf{7}}$ cycles, $\mathbf{M P a}$ \\
\hline As-fabricated & $Z$ & 0.19 & 78.1 & 2.3 & 407 \\
As-fabricated & $X-Y$ & 0.11 & 96.9 & 0.99 & 441 \\
HIP & $Z$ & 0.00 & 83.1 & 0.09 & 538 \\
HIP & $X-Y$ & 0.00 & 99.0 & 1.1 & 607 \\
\hline
\end{tabular}

(Ref 20). The porosity in the as-fabricated specimens was report to be less than $50 \mu \mathrm{m}$ in diameter and was attributed to argon gas entrapment. HIP processing eliminated the residual porosity and enhances properties. Fatigue strength of the HIPed alloy in the $\mathrm{Z}$ orientation is $24 \%$ greater than in the as-fabricated condition. Similarly, the fatigue strength of the HIPed alloy in the $X-Y$ orientation is $27 \%$ greater than in the as-fabricated condition. Fatigue strength in the $X-Y$ orientation is nearly $8 \%$ greater than in the $Z$ orientation for the as-fabricated material; in the HIPed condition, the fatigue strength is $11 \%$ greater.

Surface finish also affects fatigue performance (Ref 23). Chan et al. investigated the effect of surface roughness on the fatigue life of EBM \&LBM Ti-6Al-4V using an ARCAM and EOS, respectively. They employed a three point bend test with a maximum surface stress of $600 \mathrm{MPa}$ and a stress ratio, $R$, of 0.1 . They found that the fatigue life of rolled Ti-6Al-4V $>$ LBM $>$ EBM fabricated alloys. They correlated fatigue life to surface finish, and from their data, Eq 1 can readily be derived

$\ln ($ fatigue life $)=-0.34 \ln ($ Surface Rougness $)+$ Constant

Very roughly, this means as surface roughness increases from 3 to $1000 \mathrm{Ra}$, the fatigue life decreases from $10^{5}$ to $10^{4}$ cycles.

Greitemeir et al. (Ref 24) investigated the properties and microstructure of Ti-6Al-4V produced using electron beam powder bed (EBPB) and laser beam powder bed (LBPB) techniques as well as wire fed laser beam (WFLB). They reported that the morphology of the porosity for EBPB and LBPB differed significantly. The LBPB processed material exhibited irregular-shaped pores whereas the porosity of the EBPB produced alloys was spherical. With regard to high cycle fatigue life, they concluded that surface defects had the most pronounced impact on reducing high cycle fatigue life. In terms of fatigue crack growth performance, Greitemeir et al. (Ref 24) concluded that porosity was not the dominant factor rather it was the alloy's microstructure. Stated another way, they concluded that HIP closure of porosity did not have a significant impact on fatigue crack growth.

Martukanitz and Simpson (Ref 25) reported that build rate and feature definition are closely linked and related to surface quality. Figure 8 illustrates the relationship between build rate, power, and feature quality. In general, as build rate increases, feature quality/resolution decreases. The implication is that for fatigue critical parts fabricated using high deposition rate AM processes, post process surface finishing may be necessary.

The surface finish is affected by the type of equipment, the direction of build, and the process parameters used (Ref 19). Table 9 illustrates this impact.

It can be observed that the surface roughness of the build at right angles to the energy source (side) is 2-3 times as rough as the surfaces parallel to the energy source (top). It may be further noted that the DMLS systems produce surfaces approximately twice as smooth as the EBM. Surface condition is most important for fatigue critical parts intended for use in their as-fabricated, net shape condition. This is especially relevant for parts with complex internal features where surface finishing may be impracticable.

In summary, when properly processed, the static mechanical properties of AM metallic materials are comparable to conventionally fabricated metallic components. The relatively high cooling rates achieved reduce partitioning and favor reduced grain sizes. However, AM fabricated materials do exhibit microstructural and mechanical property anisotropy with the $Z$-direction generally being the weakest. Dynamic properties of AM produced alloys are dominated by defect structures, viz., 


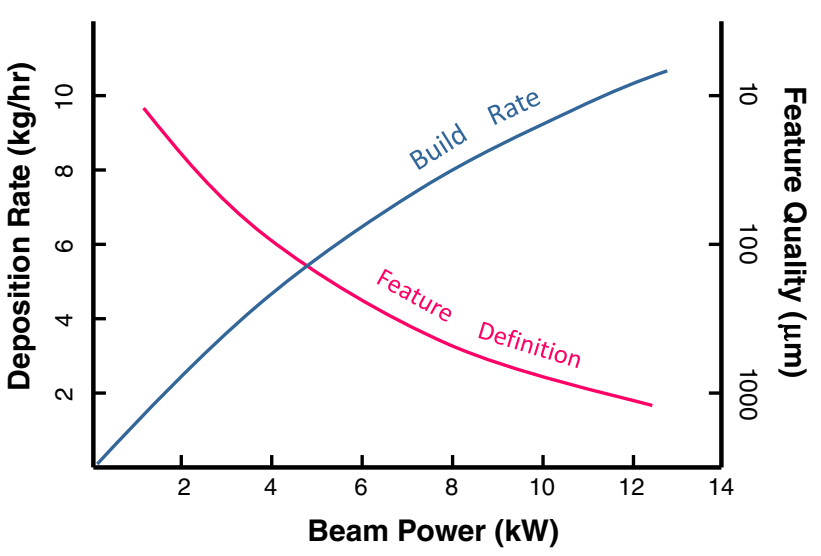

Fig. 8 Relationship between build rate, power, and feature definition

Table 9 Surface roughness for the DMLS and EBM processes

\begin{tabular}{llcc}
\hline Process & Equipment & $\begin{array}{c}\text { Roughness, } \\
\text { Ra (side) }\end{array}$ & $\begin{array}{c}\text { Roughness, } \\
\text { Ra (top) }\end{array}$ \\
\hline DMLS & M270 & 306 & 132 \\
DMLS & M280 & 331 & 116 \\
EBM & ARCAM & 594 & 199 \\
\hline
\end{tabular}

micro-porosity and surface finish. However, properly processed HIPed and finished machined AM alloys can exhibit fatigue properties on parity with those of wrought alloys.

\section{Qualification, Process Models, Sensors, and Controls}

The development of closed-loop, real-time, sensing, and control systems is essential to the qualification and advancement of AM (Ref 2,3). This involves the development of coupled process-microstructural models, sensor technology, and control methods and algorithms.

The microstructural evolution of Ti-6Al-4V has been investigated and modeled for a variety of $\mathrm{AM}$ and thermal mechanical processes ( $\operatorname{Ref} 8,26,27)$. AM is a uniquely complex process of layer by layer deposition. During this process, the thermal history of a layer may involve multiple re-melt and solidification cycles as well as multiple solid state phase transformations. The development of validated models is needed to accurately predict the structure and properties of the deposit.

Melt pool size and shape are features that should be controlled in order to produce materials of consistent quality. Beuth and Klingbeil (Ref 28) have developed process maps for predicting melt pool size and related these properties to deposition rate and power. By doing so, he has shown that it is possible to maintain a constant melt pool size over a range of deposition rates.

Lambrakos and Cooper (Ref 15, 16) identified the important process parameters to include: (i) laser or e-beam power (power density, focus, and effect in z-direction), (ii) powder or wire feed rate (focus and $\mathrm{z}$ range of build), (iii) traverse velocity, (iv) Hatch $(x-y)$ spacing, and (v) $z$ increment. Due to the lack of thermo-physical data, they used what they called the inverse approach. That is, basic equations of theory are augmented by experimental data.

The qualification of AM equipment is critical to the adoption of $\mathrm{AM}$ and is a necessary prerequisite to the certification of structural components. Presently, there is variability from part-to-part and from machine to machine (Ref 3, 6). A process by which a material's technology is qualified for use varies; however, certain elements are generally required. Frazier et al. (Ref 29) reports that there are three basic questions which must be addressed.

1. Has the materials technology been developed and standardized? The materials must be produced according to a fixed process specification.

2. Has the materials technology been fully characterized? Statistically substantiated mechanical property minimum data must be generated consistent with MMPDS (Ref 30). For example, the A-basis allowable requires that $99 \%$ of the population is to equal or exceed the reported mechanical property value with a confidence level of $95 \%$.

3. Has the materials technology been demonstrated? The materials technology subcomponent must be demonstrated in a relevant operational environment.

The qualification of AM for structurally critical applications represents significant challenge because of the following.

1. AM is a rapidly evolving nascent manufacturing technology and with a large number of diverse AM units.

2. Standardization, i.e., freezing the process, is the first step in the conventional qualification process. Freezing the process is antithetical to AM processing. However, the ASTM F42 Committee is working to overcome this challenge. ASTM and SAE have issued several standards on AM addressing terminology, file format, and the processing of Ti-6Al-4V (Ref 18, 31-34).

3. There are significant cost and time barriers to the generation of the needed mechanical property data.

The conventional mean of qualifying and certifying aircraft components is costly ( $>\$ 130 \mathrm{~m})$ and lengthy ( $\sim 15$ years) (Ref 35). The development of a statistically substantiated database alone can cost $\$ 8-\$ 15 \mathrm{~m}$, require the testing of 5,000100,000 specimens, and take over 2 years. Hence, technological alternative means of accelerated qualification are needed (Ref 36). DARPA is pursuing this under the DARPA Open Manufacturing Program, the Navy is pursuing it under a DDM ACT project, and NAMII has solicited proposal in this area (Ref 35$)$.

\section{Business Considerations}

In developing a business case for the use of AM vice conventional manufacturing methods, many factors must be taken into account. Some of these include (i) fixed cost/ nonrecurring manufacturing costs, (ii) the cost of process qualification and component certification, (iii) logistical costs, and (iv) the cost of time. Cost estimation techniques include (i) 
analogy based, (ii) parametric, and (iii) engineering (Ref 37). Further, the method of allocating cost is also relevant and includes (i) activity-based costing, (ii) total life cycle costs, (iii) target costs, and (iv) full costing (Ref 37-40).

The UK Technology Strategy Board reported on shaping the national (UK) competency for AM. In 2011, AM sales were valued at $\$ 1.9 \mathrm{~B}$ with a sustained double digit growth. Based upon projections, sales are expected to grow at a rate of $\$ 7.5 \mathrm{~B} /$ year by 2020; however, if the barriers to AM are addressed, sales could exceed \$100B/year (Ref 41). The principle barriers to full realization of this target were identified as cost, quality, range of materials, and size limitations. Among the areas that were identified as needing work were (i) increase in deposition rate by $4-10 \times$, lower material costs, in-process, closed-loop control systems to reduce process variance, training for designers of AM, industry standards for AM qualification, and materials optimized for AM.

Gnam et al. (Ref 42) examined LENS repair of IN 625 3rd stage turbine blades at the Anniston Army Depot. They found savings of $\$ 6,297 /$ part or $\$ 1,444,416 /$ year. For an AV8B Ti$6 \mathrm{Al}-4 \mathrm{~V}$ engine blade tip repair, Kelly (Ref 43) calculated an $81 \%$ cost saving at a value of $\$ 715 \mathrm{k} /$ year. Phinazee (Ref 44 ) describes the benefits of using the Sciaky EBFFF process to fabricate a typical Ti-6Al-4V airframe component. The AM process was found to have $79 \%$ greater material utilization efficiency, and the fabrication cost was reduced from $\$ 17,430$ to $\$ 9,810$. Kinsella investigated the deposition of IN718 alloy features on a forged engine case. A 30\% cost savings were realized using electron beam wire deposition as compared to conventional fabrication methods (Ref 45). Lockheed Martin (LM) is pursing the application of AM Ti-6Al-4V on the JSF (Ref 46). Considerable potential cost saving was identified for parts such as the F-35 CTOL/STOVL Flaperon Spar. Brice, Needler, and Rosenberger quote a LM VP for global integration, "This new process offers the potential to save between 30 and $50 \%$ of the cost of machining aerospace titanium structural components, which are some of the most expensive components in the F-35 airframe."

Wide spread acceptance of AM necessarily implies that manufactures can be profitable. Factors favoring AM are listed in Table 10 .

The cost associated with manufacturing can be divided into costs which are fixed and those which are recurring. Fixed costs include such things as tools, dies, buildings, etc. These costs must be amortized over the number of items produced. Recurring costs are cost such as materials, labor, etc. These costs are more directly associated with a part being produced.

Table 10 Factors favoring AM Vice conventional manufacturing

Favor AM Favor conventional manufacturing

Low production volumes

High material cost

High machining cost

Capital investment

Logistics costs

Transportation costs

Prototyping
Figure 9 is a notional graph illustrating the cost of producing parts via conventional means and AM. Total cost is seen to be a linear function of " $x$ " number of parts being produced. The $Y$-intercept of the lines represents the fixed cost, while the slope is the ratio of the recurring cost of the process divided by the recurring cost of conventional manufacturing. The assumptions made in this illustration are (1) that the fixed costs of AM are one tenth of those of conventional manufacturing, and (2) the recurring costs of AM are higher by $1.5 \times$ and $2 \times$, respectively.

In conducting a business case assessment (BCA), both fixed and recurring cost must be examined. In general, conventional manufacturing involving metal working, machining, etc. have higher fixed costs, e.g., tools, dies, and manufacturing floor space. However, their recurring costs are typically less expensive than AM, e.g., raw materials. This makes conventional manufacturing processes more competitive for large production lots.

As can be seen from Fig. 9, the cross-over point (point of equivalent cost) is dependent upon the ratio of recurring cost of $\mathrm{AM}$ to recurring cost of conventional manufacturing. In this example, the breakeven point for a recurring cost ratio of 2 is around 90, whereas it is 175 for a recurring ratio of 1.5 . For a recurring cost ratio of 1 , AM costs would be lower at all production volumes. Since the cost of raw materials (powder and wire) is significant recurring costs drivers for AM, there will be continued emphasis on their cost reduction.

In summary, the business case assessment will drive the application of AM. AM is currently favored in small production lots in which the higher cost of AM specific raw materials is offset by a reduction in fixed costs associated with conventional manufacturing. A value can be placed on the speed, versatility, and adaptability of AM, because it allows for just-in-time manufacturing. Although this type of savings may be harder to quantify, it seems clear that if one can fabricate a critical part (perhaps needed to keep a system operational) in days vice weeks, AM provides a value. Further, for large organization such as DoD, the cost of maintaining part inventory can be costly and complicated (Ref 6). AM has the potential to reduce the logistical footprint, cost, and energy associated with the packaging, transport, and storage of spare parts. The impact on the logistical supply chain has yet to be fully analyzed.

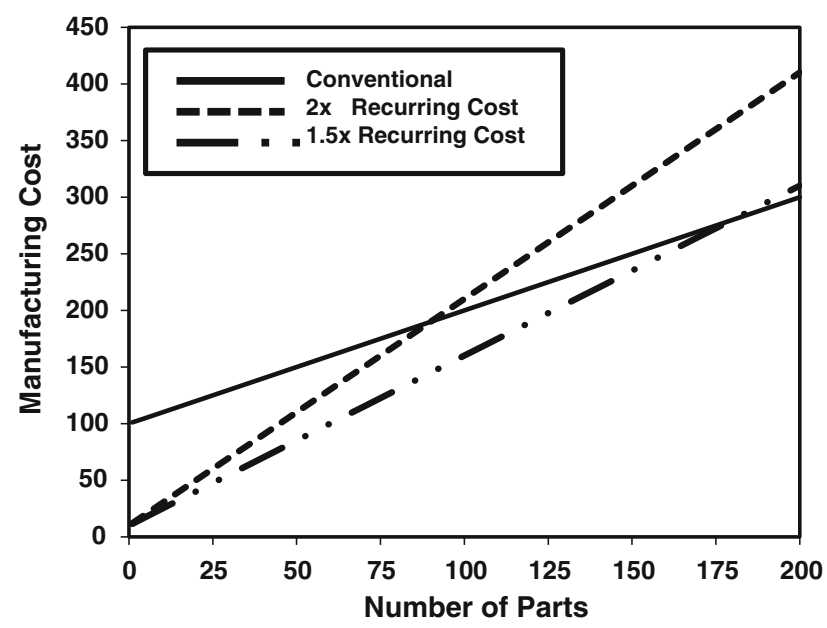

Fig. 9 Low volume business case for AM vice conventional fabrication methods 


\section{Environment, Energy Consumption and Carbon Footprint}

Drizo and Pegna (Ref 47) reviewed the state-of-the-art environmental impact assessment (EIA) of rapid prototyping. A variety of methods were examined to measure environmental impact including life-cycle analysis (LCA), environmental impact scoring systems (EISS), and design for environment (DFE). They found that the scarcity of research and the rapid evolution of this technology left a large number of unresolved issues (Ref 47). The authors recommend a joint effort of process control engineers, designers, and environmental specialist to assess the impact.

Morrow et al. (Ref 48) examined the environmental impact of laser-based AM vice conventional manufacturing for the fabrication of tool and dies. Three case studies were presented, and quantitative estimates were generated for energy consumed, and the emissions produced. It was found that laserbased remanufacturing of tooling had the greatest potential to reduced environmental impact and cost. Further, the authors describe a complex set of trade-offs between economic, environmental ramifications, and manufacturing processes. Luo et al. (Ref 49) reported on an environmental assessment of solid FFF. They reported that the waste stream is much less in SFF processes that in conventional manufacturing.

Kellens et al. (Ref 50) examined the energy efficiencies of the selective laser sintering (SLS) and the selective laser melting processes (SLM). The methodology employed was Cooperative Effort on Process Emissions in Manufacturing (CO2PE!) initiative (Ref 51). The authors point out that quantitative analyses of the environmental impact of SFF processes are very limited and that the detailed information needed regarding energy consumption, waste flows, and emissions is often lacking (Ref 2). Scot et al. (Ref 6) confirmed this assessment stating, "To date, few studies have examined the variety of environmental impacts of AM." Their analysis does a nice job in defining the system-level boundaries for which environmental in and outputs are measured. The energy efficiency is the ratio of output energy content of the product/the total energy used in fabrication. For these processes, it was determined that the energy efficiency was 0.086 , or $8.6 \%$ of the total energy used goes into the part. While this is an excellent approach at the system level, it does not provide for a holistic life cycle assessment.

Unocic and Dupont (Ref 52) examined the efficiency of LENS processes use to produce $\mathrm{H}-13$ tool steel and copper powder deposits. The measured laser energy transfer efficiency ranged from $30-50 \%$. The laser energy transfer efficiency is the ratio of the energy absorbed by the work piece divided by the energy of the heat source. Further, under optimum conditions, they found that the maximum deposition efficiency was approximately $14 \%$.

Sreenivasan and Bourell (Ref 53) examined the SLS process from an energy use stand point. The system investigated was the \#D Systems Vanguard. The average power consumed was $19.6 \mathrm{~kW}$, and the primary sources of energy consumption were (i) chamber heater, $36 \%$, (ii) stepper motors, $26 \%$, the roller drives, $16 \%$, and the laser, $16 \%$. They concluded that the SLS process was a sustainable system due to its low energy consumption, minimal waste products, and a favorable total energy indicator.

AM holds the potential to reduce carbon footprint through design optimization and the reduction in the material waste stream. The ATIKINS project concluded that an optimal design could show a weight and material saving of almost $40 \%$ (Ref 54). Their analysis showed that for long range aircraft, reducing the weight of an aircraft by $100 \mathrm{~kg}$ results in both a $2.5 \mathrm{~m}$ dollars saving in fuel and a $1.3 \mathrm{MtCO}_{2}$ savings over the lifetime of the aircraft.

It is clear that more work needs to be done to investigate the impact of AM on the environment. A systems approach which spans the cradle to grave life cycle of AM fabricated component(s) is needed to capture the true benefits and possible pitfalls of using AM. It appears that components designed to exploit the unique weight savings characteristics of $\mathrm{AM}$ hold the greatest potential to reduce environmental impact.

\section{Summary and Conclusions}

$\mathrm{AM}$ is a process of making parts from 3D model data. Usually, the parts are fabricated layer upon layer vice convention subtractive (e.g., machining, milling, etc.) means. There are a large number of diverse pieces of AM equipment commercially available, and their numbers continue to grow. These may be broadly characterized as powder bed, powder fed, and wire fed systems.

During fabrication, metallic AM parts/alloys experience a complex thermal history involving directional heat extraction, and repeated melting and rapid solidification. Many alloys also experience repeated solid state phase transformations. These factors introduce complexities to the analysis of microstructural evolution and properties not typically found in conventional processes.

In general, the static mechanical properties of AM metallic materials are comparable to conventionally fabricated metallic components. The relatively high cooling rates achieved in many of the AM processes reduce partitioning and favor reduced grain sizes. Microstructural and mechanical property anisotropy is ubiquitous in AM with the Z-direction generally being the weakest. Processing defects (e.g., micro-porosity and surface finish) dominate the fatigue properties of AM produced alloys. However, HIPed and finish machined AM alloys can exhibit fatigue properties on parity with those of wrought alloys.

Qualification and certification has been repeatedly identified as a challenge to widespread adoption of AM structurally critical components; the current process is too costly and takes too long. Hence, technological alternative means of accelerated qualification are needed.

Ultimately, the business case assessment will determine the success of AM. AM is currently favored in small production lots in which the higher cost of AM specific raw materials is offset by a reduction in fixed costs associated with conventional manufacturing. Further, there is a value to be placed on the speed, versatility, and adaptability of AM as it allows for justin-time manufacturing. The economic viability of producing large production lots of AM parts depends heavily on the reduction of reoccurring costs, i.e., the cost of the starting materials used in AM fabrication.

$\mathrm{AM}$ is projected to have a positive impact on the environment by reducing energy consumption and carbon footprint. It is clear, however, that further work needs to be done. A systems approach which spans the cradle to grave life cycle of AM fabricated component(s) is needed to capture the true benefits and possible pitfalls of using AM. 


\section{Acknowledgments}

The author is gratefully to Dr. Jennifer Williams, Mr. Chris Williams, and Dr. Venkatman Manivanin for their technical review of this manuscript, and to Drs. Richard Martukanitz and Todd Palmer for providing the optical micrographs. The author also wishes to thank Ms. Malinda Pagett, Mr. Anthony Zaita, Dr. Madan Kittur, Dr. Venkatman Manivanin, and Dr. Charles Lei for many enlightening discussions regarding additive manufacturing.

\section{References}

1. J. Alcisto, A. Enriquez, H. Garcia, S. Hinkson, T. Steelman, E. Silverman, P. Valdovino, H. Gigerenzer, J. Foyos, J. Ogren, J. Dorey, K. Karg, T. McDonald, and O.S. Es-Said, Tensile Properties and Microstructures of Laser-Formed Ti-6Al-4V, JMEP, 2011, 20(2), p 203-212

2. D.L. Bourell, M.C. Leu, and D.W. Rosen, Ed., Roadmap for Additive Manufacturing, University of Texas at Austin, Austin TX, 2009

3. W.E. Frazier, "Digital Manufacturing of Metallic Components: Vision and Roadmap", Solid Free Form Fabrication Proceedings, University of Texas at Austin, Austin TX, 2010, p 717-732

4. E. Herderick, Additive Manufacturing of Metals: A Review, Proceedings of MS\&T 11, Additive Manufacturing of Metals, Columbus, $\mathrm{OH}$, 2011

5. NIST, "Measurement Science Roadmap for Metal-Based Additive Manufacturing," US Department of Commerce, National Institute of Standards and Technology, Prepared by Energetics Incorporated, May 2013

6. J. Scott, N. Gupta, C. Weber, S. Newsome, T. Wohlers, and T. Caffrey, Additive Manufacturing: Status and Opportunities, IDA, Science and Technology Policy Institute, Washington, DC, 2012

7. DoD SBIR/STTR Database (https://www.dodsbir.net, Contracts N00014-12-C-0411， N00014-12-C-0221，N00014-13-C-0057， Nov 2013

8. S.M. Kelly and S.L. Kampe, Microstructural Evolution in LaserDeposited Multilayer Ti-6Al-4V Builds: Part II. Thermal Modeling, Metall. Trans. A., 2004, 35A, p 1869-1879

9. F. Wang, S. Williams, P. Colegrove, and A.A. Antonysamy, Microstructure and Mechanical Properties of Wire and Arc Additive Manufactured Ti-6Al-4V, Metall. Trans. A., 2013, 44A, p 968-977

10. B. Zheng, Y. Zhou, J.E. Smugeresky, J.M. Schoenung, and E.J. Lavernia, Thermal Behavior and Microstructural Evolution during Laser Deposition with Laser-Engineered Net Shaping: Part I. Numerical Calculations, Metall. Trans. A., 2013, 39A, p 2237-2245

11. T. Vilaro, C. Colin, and J.D. Bartout, As-fabricated and Heat-Treated Microstructures of the Ti-6Al-4V Alloy Processed by Selective Laser Melting, Metall. Trans. A., 2011, 42A, p 3190-3199

12. B. Zheng, Y. Zhou, J.E. Smugeresky, J.M. Schoenung, and E.J. Lavernia, Thermal Behavior and Microstructure Evolution during Laser Deposition with Laser-Engineered Net Shaping: Part II. Experimental Investigation and Discussion, Metall. Trans. A., 2008, 39A, p 2228

13. P.A. Kobryn and S.L. Semiatin, The Laser Additive Manufacturing of Ti-6Al-4V, JOM, 2011, 53, p 40-43

14. L.E. Murr, E. Martinez, S.M. Gaytan, D.A. Ramirez, B.I. Machado, P.W. Shindo, J.L. Martinez, F. Medina, J. Wooten, D. Ciscel, U. Ackelid, and R.B. Wicker, Microstructural Architecture, Microstructures, and Mechanical Properties of a Nickel-Base Superalloy Fabricated by Electron Beam Melting, Metall. Trans. A., 2011, 42A, p 34913508

15. S.G. Lambrakos and K.P. Cooper, An Algorithm for Inverse Modeling of Layer-by-Layer Deposition Processes, JMEP, 2009, 18(3), p 221230

16. S.G. Lambrakos and K.P. Cooper, A General Algorithm for Inverse Modeling of Layer-by-Layer Deposition Processes, JMEP, 2010, 19(3), p 314-324

17. F. Wang, S. Williams, P. Colegrove, and A.A. Antonysamy, Microstructure and Mechanical Properties of Wire and Arc Additive Manufactured Ti-6Al-4V, Metall. Trans. A., 2013, 44A, p 968-977

18. AMS 4999 Specification, Titanium Alloy Laser Deposited Products 6Al-4V Annealed, SAE, Warrendale, PA 2002
19. S. Rengers, Electron Beam Melting [EBM] vs. Direct Metal Laser Sintering [DMLS], Presented at SAMPE Midwest Chapter, Direct Part Manufacturing Workshop, Wright State University, Nov 2012

20. M. Svensson, Ti6A14V manufactured with Electron Beam Melting (EBM): Mechanical and Chemical Properties, Presented at Aeromat 2009, Dayton OH, Jun 2009

21. M.K.E. Ramosoeu, G. Booysen, T.N. Ngonda, and H.K. Chikwanda, Mechanical Properties of Direct Laser Sintered Ti-6Al-V4, MS\&T'11, Columbus, OH, 2011

22. B. Baufeld, Mechanical Properties of INCONEL 718 Parts Manufactured by Shaped Metal Deposition (SMD), JMEP, 2012, 21(7), p 14161421

23. K.S. Chan, M. Koike, R.L. Mason, and T. Okabe, Fatigue Life of Titanium Alloys Fabricated by Additive Layer Manufacturing Techniques for Dental Implants, Metall. Trans. A., 2013, 44A, p 10101022

24. D. Greitemeir, K. Schmidtke, V. Holzinger, and C. D. Donne, Additive Layer Manufacturing of Ti-6Al-4V and Scalmalloyrp $\odot$ Fatigue and Fracture, 27th ICAF Symposium, Jerusalem, June 2013

25. R. Martukanitz and T. Simpson, The Center for Innovative Materials Processing through Direct Digital Deposition (CIMP-3D), Brief at the Technology Showcase, ARL Penn State, State College, PA Jan 2013

26. C. Charles, "Modeling microstructure evolution of weld deposited Ti6Al-4V," Ph.D. thesis, Lulea University of Technology, Lulea, Sweden, 2008

27. S.M. Kelly, "Thermal and Microstructure Modeling of Metal Deposition Processes with Application to Ti-6Al-4V," Ph.D. thesis, Virginia Polytechnic Institute, VA, 2004

28. J. Beuth and N. Klingbeil, The Role of Process Variables in LaserBased Direct Metal Solid Freeform Fabrication, JOM, 2001, 53, p $36-$ 39

29. W.E. Frazier, D. Polakovics, and W. Koegel, Qualifying of Metallic Materials and Structures for Aerospace Applications, JOM, 2001, 53, p $16-18$

30. Metallic Materials Properties Development and Standardization (MMPDS-02). FAA, Battelle Memorial Institute, Atlantic City, NJ, 2005

31. ASTM F2921-11, Standard Terminology for Additive ManufacturingCoordinate Systems and Test Methodologies, ASTM International, West Conshohocken, PA, 2011

32. ASTM F2792-12a, Standard Terminology for Additive Manufacturing Technologies, ASTM International, West Conshohocken, PA, 2012

33. ASTM F2915-12, Standard Specification for Additive Manufacturing File Format (AFM) Version 1.1., ASTM International, West Conshohocken, PA, 2012

34. ASTM F2924-12, Standard Specification for Additive Manufacturing Titanium-6 Aluminum-4 Vanadium with Powder Bed Fusion, ASTM International, West Conshohocken, PA, 2012

35. M. Maher, Open Manufacturing, Brief Presented at the SAMPE Direct Part Manufacturing Workshop, Dayton OH, 2012

36. T.H. Benson Tolle, and G.A. Shoeppner, Accelerating Materials Insertion by Evolving the DoD Materials Qualification-Transition Paradigm, AMMITAC Q., 2002, 6(1), p 3-6

37. M. Ruffo, C. Tuck, and R. Hague, Cost Estimation for Rapid Manufacturing: Laser Sintering Production for Low to Medium Volumes, J. Eng. Manuf. Proc. IMech E, 2006, 220B, p 1417-1427

38. A. Gunasekaran, Design of Activity-Based Costing in a Small Company: A Case Study, Comput. Ind. Eng., 1999, 37, p 413-416

39. T. Wen-Hsien, Activity-Based Costing Model for Joint Products, Proc. 18th International Conference on Computers and Industrial Engineering, Vol. 31(3/4), Computers Industrial Engineering, 1996, p. 725-729

40. A. Gunaesekaran, R. McNeil, and D. Singh, Activity Based Management in a Small Company: A Case Study, Prod. Plan. Control, 2000, 11(4), p 391-399

41. Materials KTN, Shaping Our National Competency in Additive Manufacturing, 27th ed., Additive Manufacturing Special Interest Group for the Technology Strategy Board, UK, 2012

42. M. Gnam, R. Plourde, and T. McDonald, "Laser Engineered Net Shaping (LENS)," Paper Presented at the National Center for Manufacturing Sciences, JTEG Business Meeting, 2000

43. S.M. Kelly, Cost Benefit Analysis of Direct Digital Manufacturing, Private Communications, ARL Penn State University, 2010

44. S. Phinazee, Efficiencies: Saving Time and Money with Electron Beam Free Form Fabrication, Fabricator, 2007, p 15-20 
45. M.E. Kinsella, Additive Manufacturing of Superalloys for Aerospace Applications, WPAFB AFRL, Report Number AFRL-RX-WP-TP2008-4318, Dayton OH 2008

46. C.A. Brice, S.D. Needler, and B.T. Rosenberger, Direct Manufacturing at Lockheed Martin Aeronautics Co., Paper Presented at AeroMat Conference, Seattle Washington, 2010

47. A. Drizo and J. Pegna, Environmental Impacts of Rapid Prototyping: An Overview of Research to Date, Rapid Prototyp. J., 2006, 12(2), p 64-71

48. W.R. Morrow, H. Qi, I. Kim, J. Mazumder, and S.J. Skerlos, Environmental Aspects of Laser-Based and Conventional Tool and Die Manufacturing, J. Clean. Prod., 2007, 15, p 932-943

49. Y. Luo, Z. Ji, M.C. Leu, and R. Caudill, Environmental Performance Analysis of Solid Freeform Fabrication Processes, IEEE 0-7803-54958/99, 1999

50. K. Kellens, E. Yasa, Renaldi, W. Dewulf, J.P. Kruth, and J.R. Duflou, Energy and Resource Efficiency of SLS/SLM Processes, Proceedings
Twenty-Second Annual International Solid Freeform Fabrication Symposium, 2011

51. M. Goedkoop, R. Heijungs, M. Huijbregts, A. De Schryver, J. Struijs, and R. van Zelm, ReCiPe 2008 A Life Cycle Impact Assessment Method Which Comprises Harmonised Category Indicators at the Midpoint and the Endpoint Level, Ruimte en Milieu Ministerie van Volkshuisvesting, Ruimtelijke Ordening en Milieubeheer, http:// www.mech.kuleuven.be/co2pe, 2013

52. R.R. Unocic and J.N. DuPont, Process Efficiency Measurements in the Laser Engineered Net Shaping Process, Metall. Trans. B, 2004, 35B, p 143-152

53. R. Sreenivasan and D. Bourell, Sustainability Study in Selective Laser Sinterin: An Energy Perspective, Conference Proceedings, University of Texas at Austin, Austin TX, 2009, p 257-265

54. ATKINS, Manufacturing a Low Carbon Footprint, Loughborough University Project No: N0012J, 2007 